\title{
Reconstructing forest-cover change in the Swiss Alps between 1880 and 2010 using ensemble modelling
}

\author{
Janine Bolliger ${ }^{1} \cdot$ Dirk Schmatz $^{1} \cdot$ Robert Pazúr $^{1} \cdot$ Katarzyna Ostapowicz $^{2}$. \\ Achilleas Psomas ${ }^{1}$
}

Received: 5 July 2016/ Accepted: 4 December 2016/Published online: 31 January 2017

(c) Springer-Verlag Berlin Heidelberg 2017

\begin{abstract}
Understanding drivers of forest-cover change is essential for a broad range of ecosystem properties. In this work, we assessed changes in forest cover using physical, climatic and socio-economic drivers, including forest neighbourhood effects representing spatial interactions within and between two time periods (1880-1940; 1940-2010), for a mountainous study area located in eastern Switzerland. The robust assessment relied on an ensemble modelling approach that combined projections of six statistical models (GAM, CART, ANN, RF, GBM, GLM). A generic neighbourhood variable (distance to forest edge) explained most of the forest-cover change (variable importance of $>90 \%$ ) for both forest gain and loss, whereas socio-economic, physical and climatic variables were of least importance. The performance of models of forest loss was consistently higher and less varied (TSS of model ensembles 0.65-0.82) compared to models of forest gain (TSS of model ensembles 0.2-0.62) independent of the time period considered. We concluded that (a) the relative importance of drivers for the simulated processes is independent of the time period considered;
\end{abstract}

Janine Bolliger and Achilleas Psomas have contributed equally to this paper.

Electronic supplementary material The online version of this article (doi:10.1007/s10113-016-1090-4) contains supplementary material, which is available to authorized users.

Janine Bolliger

janine.bolliger@wsl.ch

1 WSL Swiss Federal Research Institute, Zürcherstrasse 111, 8903 Birmensdorf, Switzerland

2 Department of Geography and Spatial Management, Jagiellonian University, Gronostajowa 7, 30-387 Kraków, Poland (b) ensemble modelling proves a powerful tool to assess projection robustness by considering a suite of models rather than a single model type and (c) the inclusion of generic neighbourhood variables such as distance to forest edge improves model performance significantly.

Keywords Historical assessment - Land-change assessment - Land-use change · Land-use legacy . Socio-economic drivers $\cdot$ Biophysical drivers

\section{Introduction}

Forest cover in European mountains has significantly changed over past decades due to a combination of shifts in socio-economy and biophysical land properties as well as land management policies and politics in European mountains. Primary drivers of these shifts include declining rural population, followed by agricultural land abandonment and subsequent conversion of open land into forest across Europe (Fuchs et al. 2015; Loran et al. 2016). Although biophysical drivers such as climate are critical determinants of location of forest cover, it is understood that alterations in political or land management policies are primary drivers of land use and therefore forest-cover change (Kulakowski et al. 2011; Weisberg et al. 2013; Ameztegui et al. 2016). Continued anthropogenic influence may generate legacies for the long-term development of land use (Bolliger et al. 2004; Aggemyr and Cousins 2009; Pazur et al. 2014). Legacy assessments aim to identify the role of past land uses in shaping contemporary ecosystems and provide valuable baseline information on the spatial location and magnitude of change. However, analysis of the drivers of and relationships between past and contemporary land-use change remains a challenge (Rounsevell et al. 2012), particularly 
when assessing the sensitivity, interpretability and accuracy of the outputs of various tools to assess land change.

Among approaches, quantitative models have been shown to successfully identify and understand the variables and processes that drive land systems across a broad range of spatial and temporal scales (Van Asselen and Verburg 2013). Due to recent technological developments, computationally demanding modelling based on regression trees (Wang et al. 2016) or neural networks (Callister et al. 2016) have become key diagnostic tools in land-change science. At the same time, while widely used in climate studies and niche modelling of species, ensemble modelling (Araujo and New 2007) has gained increasing attention in ecology and land-change science (Engler et al. 2013; Regos et al. 2016; Scales et al. 2016). Ensemble modelling combines projections from a set of statistical models and allows assessment of the range of spatially explicit variability produced by the ensemble (Marmion et al. 2009). Ensemble modelling has the benefits of taking into account the magnitude and spatial extent of land change from an entire set of projections under a range of different modelling approaches. This allows for narrowing of uncertainties in land system modelling and identification of the sensitivity of land-change processes to different model types and input parameters within a spatial context.

While most quantitative land-use models employ biophysical and socio-economic variables including spatial policies as drivers (Lambin et al. 2001), neighbourhood variables and variables expressing spatial interactions are often rather generic, despite having a major impact in shaping land use (Gellrich et al. 2007; Rickebusch et al. 2007). Neighbourhood effects are known to reflect path dependencies, e.g., of land-use decisions not fully accounted for by other drivers (Dendoncker et al. 2007) or may be viewed as proxies for land change, e.g., land close to forest edges is generally less favourable for cultivation due to shading (Gellrich et al. 2007).

The aims of this paper were (a) to assess the relative predictive power of socio-economic, climatic, physical and neighbourhood drivers in shaping historical forest-cover change in a mountainous region of Switzerland for two time periods (period 1: 1880-1940; period 2: 1940-2010) using an ensemble modelling approach and (b) to analyse the performance of the ensemble approach in the context of a land-change assessment.

\section{Materials and methods}

\section{Study area}

The study was conducted for a mountainous area in the eastern part of Switzerland. The study area covered
$9513 \mathrm{~km}^{2}$ in the eastern Alps of Switzerland and ranged between 250 and $4000 \mathrm{~m}$ asl (Fig. 1). It encompassed the area of 218 communities in five cantons (Obwalden, Nidwalden, Uri, Glarus, Graubünden). The spatial pattern was a mosaic of bare land and glaciers (38\%), meadows and pastures (29\%), forest and brush forest $(28 \%)$, water and rivers $(2 \%)$, railway and roads $(1 \%)$, arable land and orchard $(1 \%)$ and $1 \%$ built-up area (SFSO 2013).

\section{Data}

\section{Response variable: forest-cover change}

Information on forest-cover change (gain and loss) was based on forest raster maps (spatial resolution $100 \mathrm{~m}$ ) obtained from historical and contemporary topographic maps for three time points: 1880, 1940 and 2010. Forest cover for 1880 relied on the first Siegfried map (Siegfriedkarten 1870-1922). For 1940, we used the latest Siegfried map of 1940 (Topographischer Atlas der Schweiz 1:25,000/1:50,000). Forest cover for 2010 relied on the topographic landscape model TLM (swissTLM ${ }^{3 \mathrm{D}}$ 2015). Based on these maps, we reconstructed forest-cover change for two time periods: $1880-1940$ (period 1) using the forest change between the first and the second Siegfried map and 1940-2010 (period 2) using the forest change between the second Siegfried map and the topographic landscape model TLM as inputs.

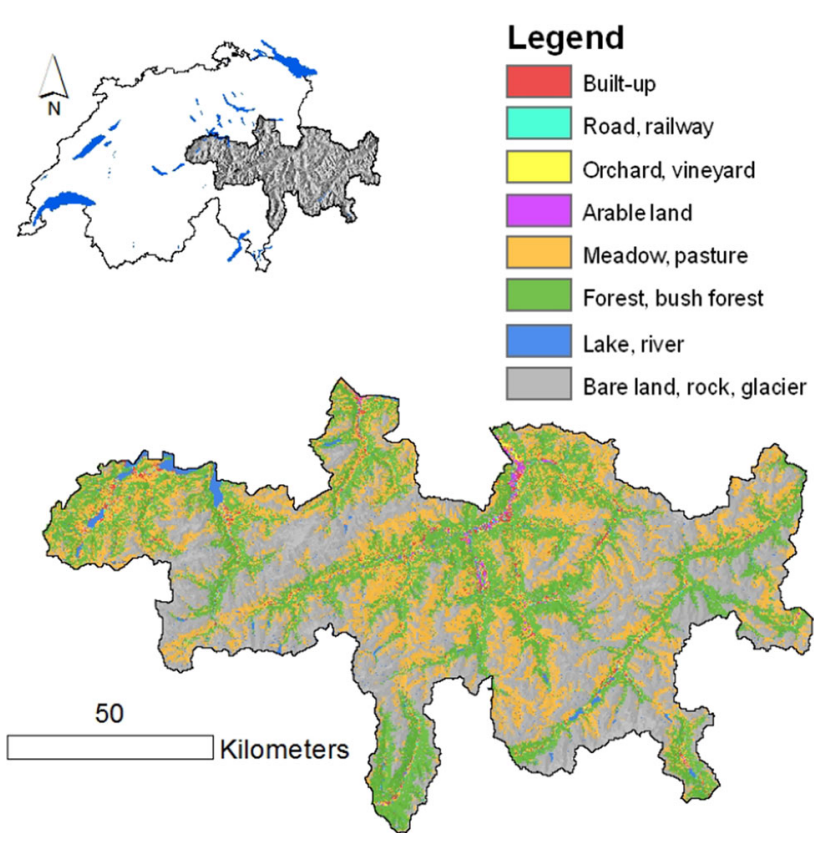

Fig. 1 Study area in the Swiss Alps 


\section{Explanatory variables}

Data sets for the explanatory variables encompassed biogeographical (climate, relief and spatial pattern) and socioeconomic variables. We initially considered a set of 32 explanatory variables (Appendix Figure A).

\section{Climate}

We used monthly climate maps covering the years 1880-2010 which rely on measured data (1901-2010) and on reconstructed climate data (1880-1900). For the years 1931-2010, the interpolation software Daymet (Thornton et al. 1997) was used to produce daily climate maps of Switzerland at $100 \mathrm{~m}$ resolution. Measured daily temperature means and precipitation sums of all available climate stations (ca. 400) of the Federal Office of Meteorology and Climatology (MeteoSwiss) and a $100 \mathrm{~m}$ elevation model aggregated from the DHM25 of the Federal Office of Topography (Swisstopo 2016) served as input. To cover the years 1880-1930, we used monthly temperature means (Luterbacher et al. 2004; Xoplaki et al. 2005) and seasonal precipitation sums (Pauling et al. 2006) generated on a $0.5^{\circ}$ resolution for Europe. We applied the change factor method (Anandhi et al. 2011) to downscale these coarsescaled data sets to the required resolution of $100 \mathrm{~m}$. From the daily Daymet maps, long-term monthly averages (temperature) and seasonal sums (precipitation) were aggregated for 1961-1990 to serve as the fine-scaled Daymet baseline period. The resulting maps were interpolated to $100 \mathrm{~m}$ and subsequently combined with the Daymet baseline period. Finally, we used the average seasonal temperature and precipitation for both time periods (Appendix Figure A).

\section{Topographic variables}

To describe relief, we used slope and aspect derived from a 25 m DEM (Swisstopo 2016). Additionally, we derived a ruggedness index (TRI) and the topographic position index (TPI) from the $25 \mathrm{~m}$ DEM. TRI is a measure for landform classification, defined as the difference between the elevation of a cell and the mean elevation of its surrounding cells (Wilson et al. 2007). TPI (Riley et al. 1999) is a normalized measure of relative position calculated using the elevation of a pixel divided by the difference of the maximum minus the minimum elevation in a given neighbourhood $(3 \times 3$ pixels in our case $)$.

\section{Distance variable}

Distance to forest relied on Euclidean distances from any location on the map to the nearest forest edge. If the chosen location was situated outside a forest, the distance had positive values; if the chosen location is inside the forest, the variable obtained negative values.

\section{Socio-economic variables}

Socio-economic data were available at the resolution of a community and collated from federal sources (Bundesamt für Statistik 2015). Two groups of socio-economic variables were considered: variables related to agriculture and variables related to demography. For both periods, agricultural variables encompassed cattle-goat ratio, number of cattle, number of goats, number of people working in agriculture, farm size and area, and number of farms (Appendix Figure A). Population variables included percentage of commuters, percentage of people employed in industries and service, road and railroad accessibility, number of households, population change, total population size, age structure of the population $(0-14,15-59,>60$; Appendix Figure A).

\section{Ensemble modelling}

We used ensemble modelling to predict forest-cover change (forest gain and loss) and to identify drivers of that change within two time periods. Probabilistic, spatially explicit models using six statistical techniques were calibrated: generalized linear models (GLM; McCullagh and Nelder 1989), generalized additive models (GAM; Hastie and Tibshirani 1986), boosted regression trees (GBM; Ridgeway 1999), random forest (RF; Breiman 2001), artificial neural networks (ANN; Ripley 1996) and classification and regression trees (CART; Breiman et al. 1984). Forest-cover change (both gain and loss) was fitted as a function of the explanatory variables to derive a spatially explicit probability distribution of forest gain and loss. A map of potential forest-cover change was obtained by a weighted combination of the projections of the six modelling techniques into an ensemble model. The weighting of projections resulting from individual models was proportional to their true skill score (TSS) (Allouche et al. 2006), a measure of model quality. The ensemble model was calculated as an average of the weighted TSS values. TSS is computed as specificity (fraction of correctly predicted presences) + sensitivity (fraction of correctly predicted absences) -1 and varies between negative values (systematically wrong), 0 (random model) and 1 (perfect agreement). For instance, a TSS of 0.6 indicated that the proportion of correctly predicted presences and absences in the data was roughly $60 \%(0.8+0.8-1=0.6)$. The ratio of forest presence/absence was therefore different for each model run. The accuracy of the model projections [within and between period 1 (1880-1940) and period 2 
(1940-2010)] was assessed using confusion matrices (Congalton and Green 2009). The accuracy assessment reflected the difference between modelled forest/non-forest versus the actual forest/non-forest pixels as derived from the Siegfried maps (1880 and 1940) and the TLM data (2010). The confusion matrices identified the overall as well as producer's and user's accuracies. The producer's accuracy referred to the probability that forest presence/ absence is modelled as such, while the user's accuracy identified the probability that a pixel classified as forest/ non-forest is really forest or non-forest given all pixels in the map (Congalton and Green 2009).

\section{Model calibration}

The models to predict forest-cover change were calibrated individually for forest gain and loss (a) within period 1 (1880-1940) and within period 2 (1940-2010) and (b) between the periods using parameter estimates of period 1 to project forest-cover change into the future and parameter estimates of period 2 to estimate forest-cover change in the past (hind-casting, Fig. 2). To assess the importance of the explanatory variables and check model performance and the resulting spatially explicit projections, we evaluated all six model types individually (GLM, GAM, GBM, RF, ANN, CART) prior to calculating the ensemble models. To ensure balanced, stratified input data for both forest gain and forest loss and to avoid hampering the statistical power with too many data points, we relied on a stratified sampling approach: points were sampled randomly within five distance strata from between forest borders (0-100, 101-200,

Model calibration

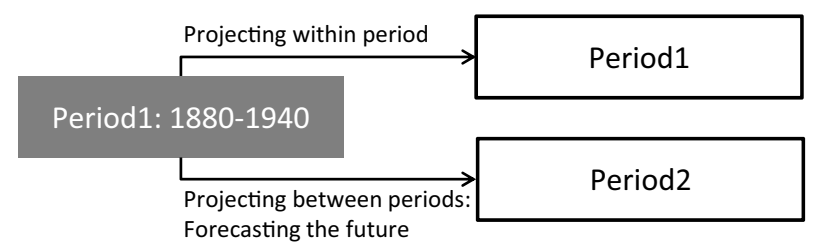

Forecasting the future

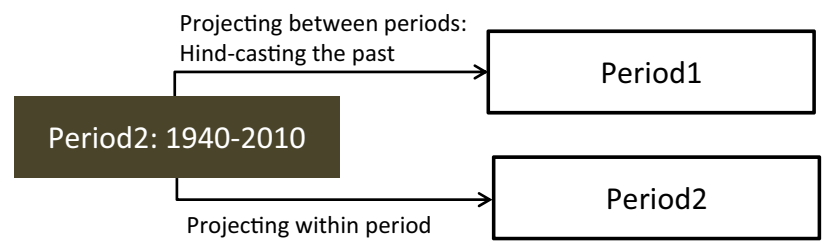

Fig. 2 Concept of analysis. Ensemble models were calibrated to explain forest gains and losses within the two time periods (period 1: 1880-1940; period 2 1940-2010). To project future forest-cover changes, parameter estimates of forest gain and loss for period 1 were applied to gain and loss of period 2. To hind-cast forest-cover change, model parameter estimates of period 2 were applied to gains and losses of period 1
201-300, 301-500 and $>501 \mathrm{~m}$ ) and for each possible change type (loss or gain) between the two time periods. The samples were spatially separated by at least $500 \mathrm{~m}$ (reducing spatial autocorrelation). For model calibration, we used five randomly chosen input data sets which contained between 200 and 2500 points (for both change and no change) per time period and consisted of 400-500 points for forest loss and 500-600 points for forest gain.

All physical, climate and socio-economic explanatory variables used to explain forest gain and loss were first checked for cross-correlation (Appendix Figure A). If cross-correlation for two variables was more than $70 \%$, only the ecologically more meaningful variable was retained in the model. Variables correlated less than $70 \%$ were all considered suitable for modelling. The importance of each variable was assessed using the VarImp function of the caret package in $R$ 3.2.2. The final selection only contained variables which were statistically significant in the models.

To evaluate the predictive power, we applied a splitsampling approach: a model was trained on $70 \%$ randomly chosen data points and evaluated on the remaining $30 \%$. Means of 30 runs (five training and evaluation runs for each of the six model types) were assessed using the true skill statistic (TSS), a measure of agreement between predicted and observed values (Allouche et al. 2006).

The six considered modelling techniques generated predictions in the form of continuous probabilities $(0-1)$ that are analogous to probabilities of presence. These probabilities were converted into presence-absence (loss or gain and no-change maps in our case) by choosing a threshold above which a prediction becomes 1 (presence) and below 0 (absence). This threshold was determined so as to optimize map accuracy which was judged by a specific accuracy measure (Freeman and Moisen 2008), in our case TSS (Allouche et al. 2006). During this process several thresholds between 0 and 1 were tested, and at each step the map accuracy was calculated for each of the six statistical model types. The threshold at which the map's accuracy was maximized was finally chosen to convert the continuous probabilities to binary.

\section{Results}

\section{Variable importance}

Overall, the forest area increased by $25 \%$ from 1701 to $2268.7 \mathrm{~km}^{2}$ between 1880 and 2010. Five variables (out of the 32 considered; Appendix Figure A) were correlated less than $70 \%$ and explained the variation in forest-cover change statistically significantly in each period (1880-1940; 1940-2010; Fig. 3): mean seasonal 


\section{A Forest gain}

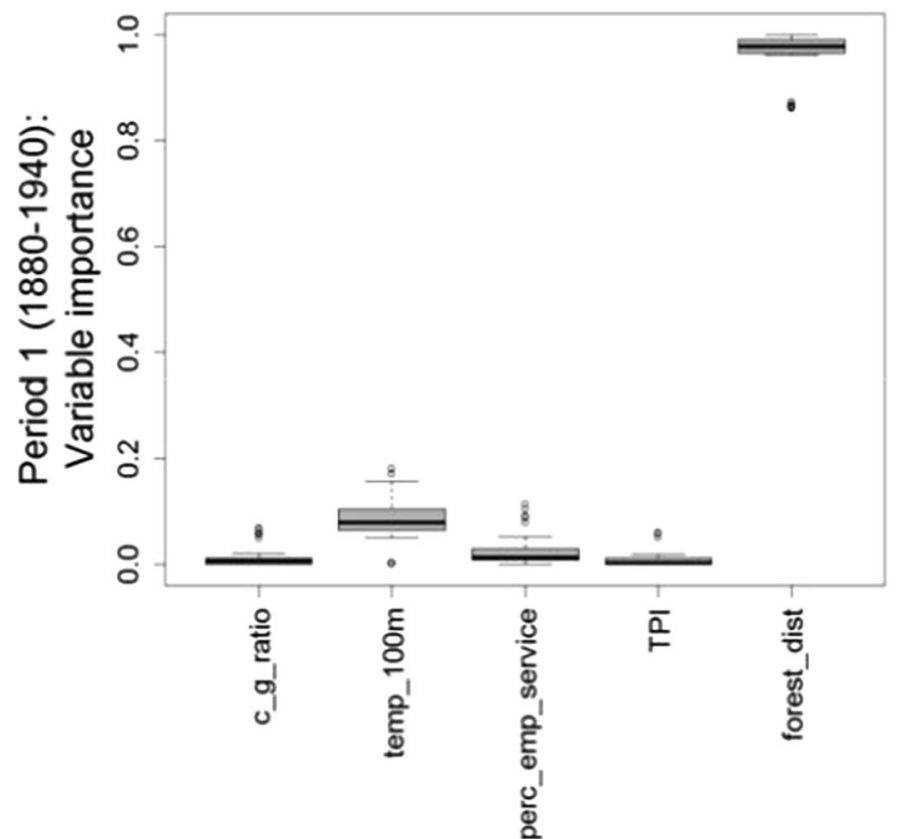

C Forest gain

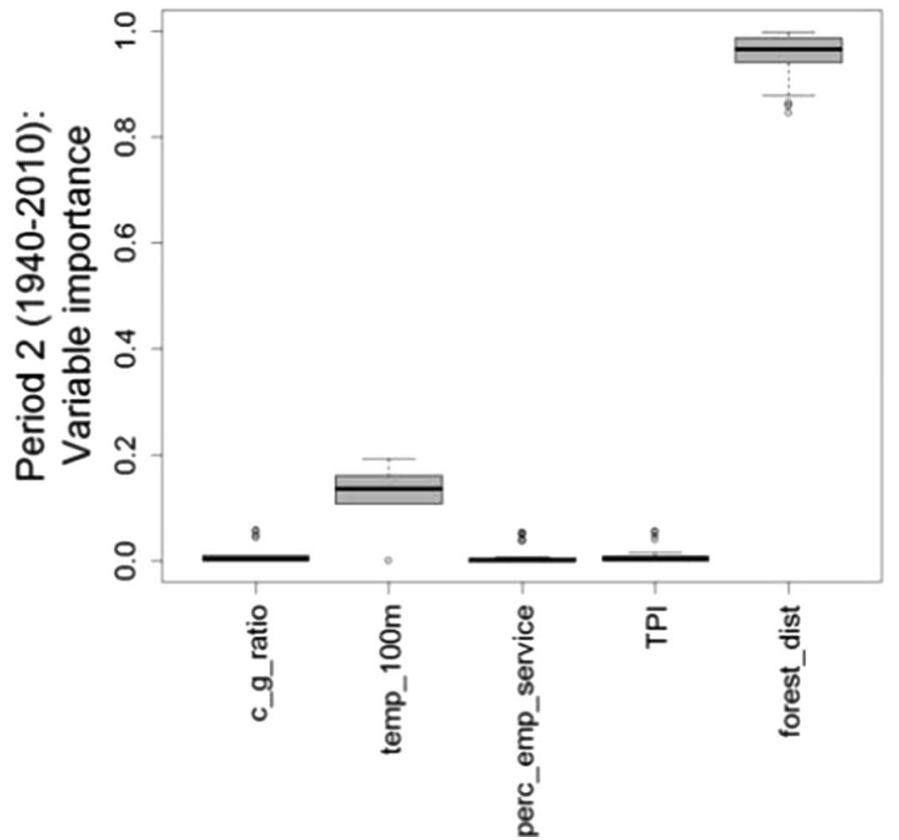

Fig. 3 Variable importance for forest gain (a) and forest loss (b) for two time periods (period 1: 1880-1940; period 2: 1940-2010). Boxplots represent mean and range of the variable importance $(0-1)$

temperature, neighbourhood (distance to forest), topography (TPI) per cent employed people in industry and public service, and either farm size (forest loss) or farm management as cattle-to-goat ratio (forest gain; Fig. 3). Distance to forest was by far the most important variable and explained over $90 \%$ of the variance of forest gain and loss for both periods (Fig. 3).

\section{B Forest loss}

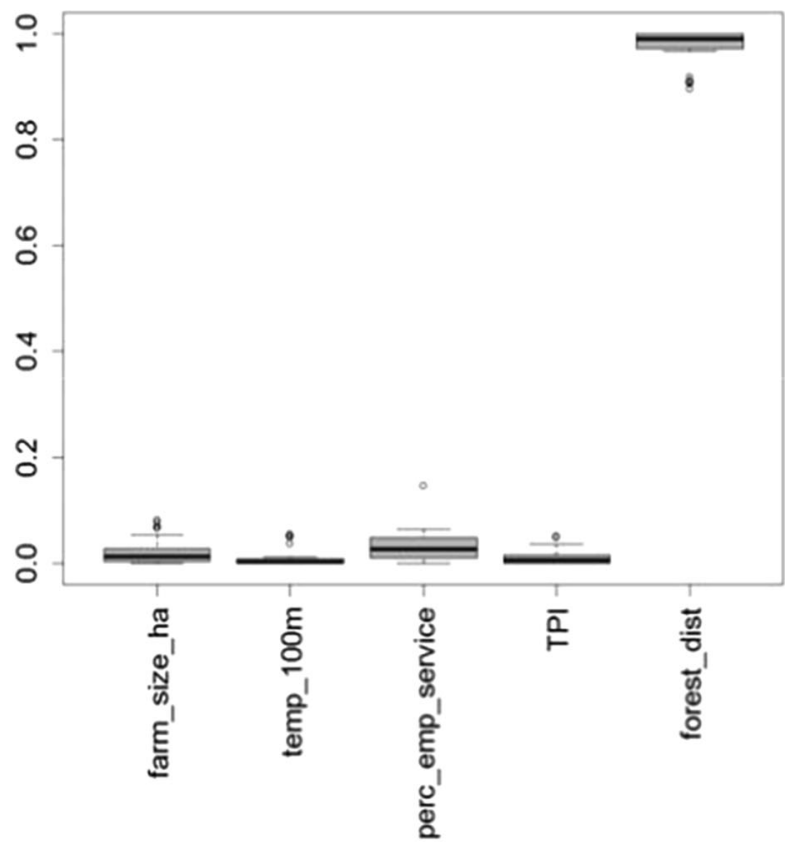

D Forest loss

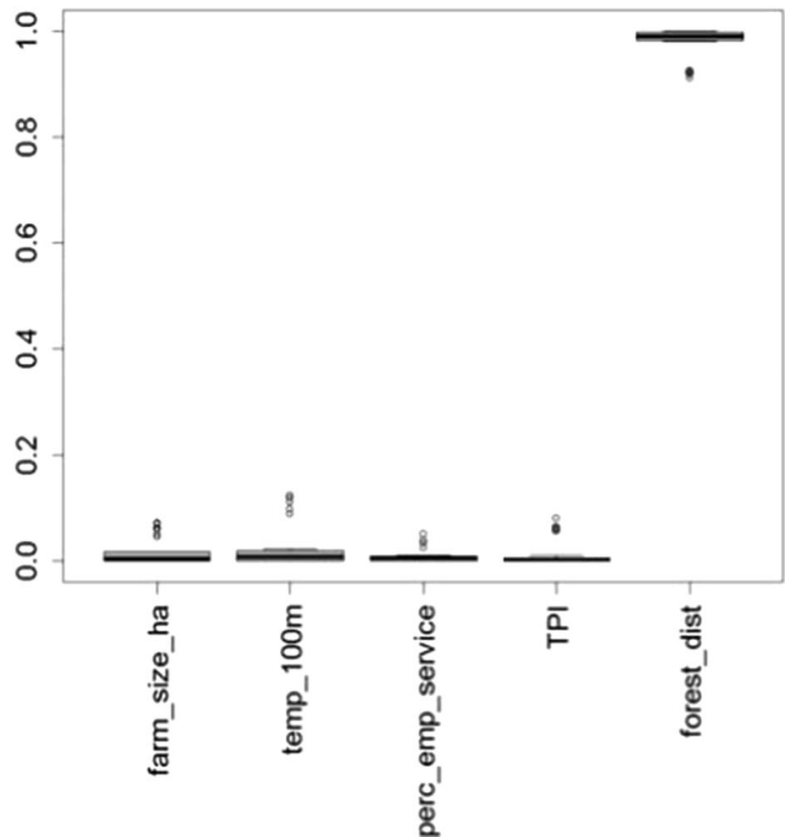

of 30 model runs [five runs for each of the six model types (GLM, GAM, RF, GBM, ANN, CART)]

\section{Model performance within time periods 1880-1940 and 1940-2010}

Considering the overall pattern of model performance within the two time periods, RF ranked consistently high for both forest gain (TSS 0.6) and loss (TSS 0.8; Fig. 4ad). There is a trend for GBMs to perform slightly higher 


\section{A Forest gain}

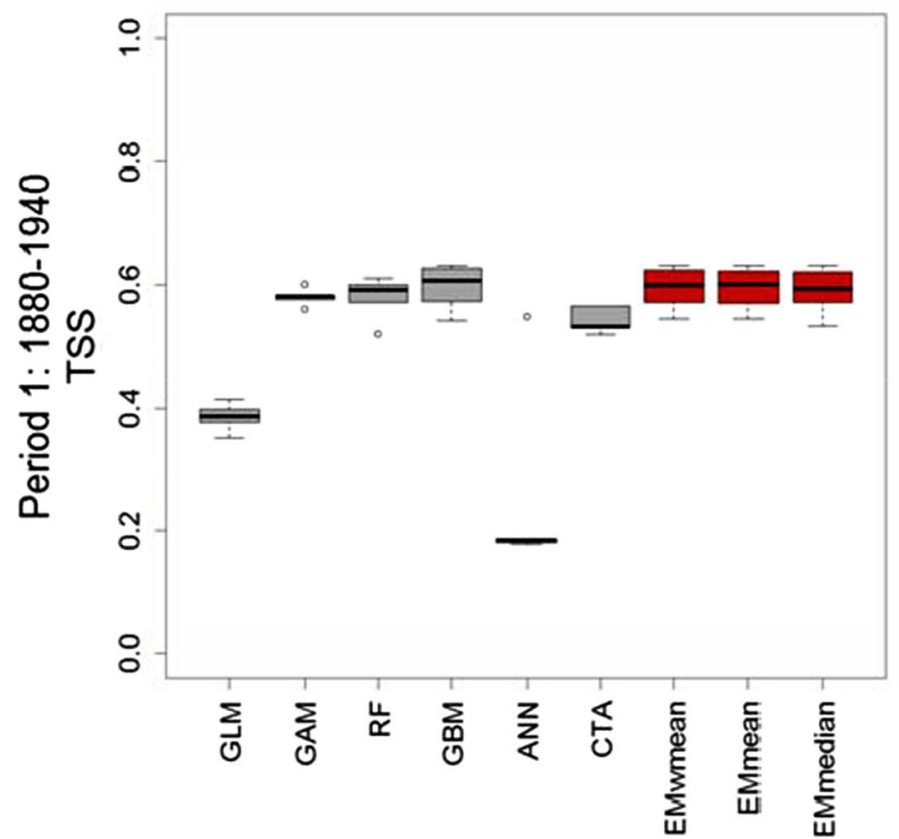

C Forest gain

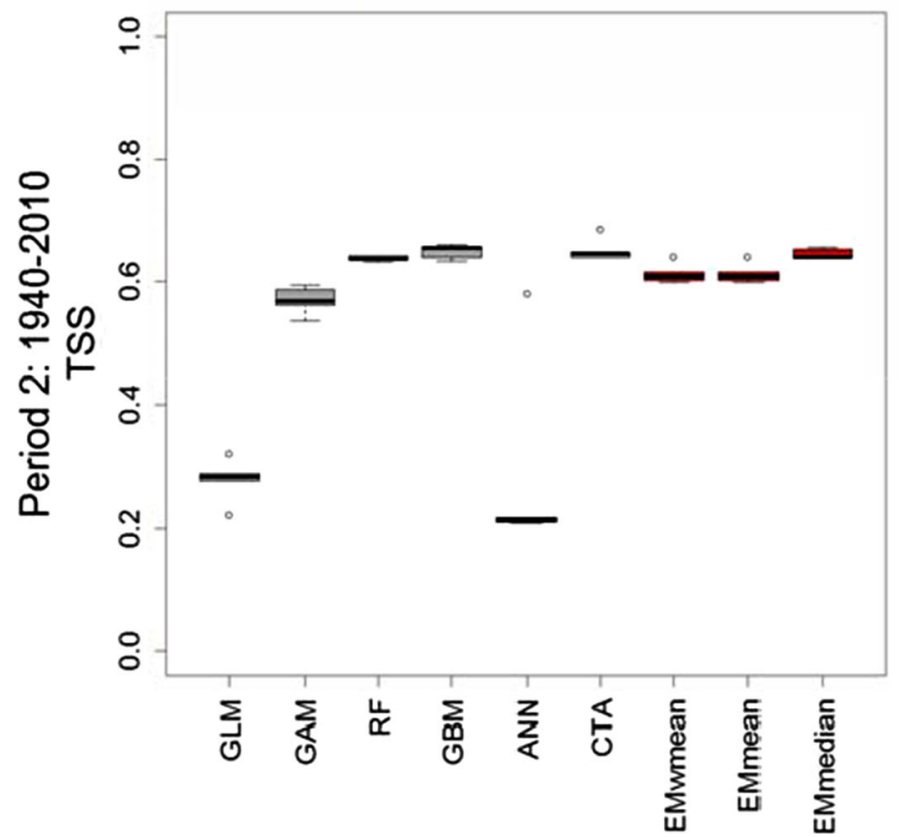

B Forest loss

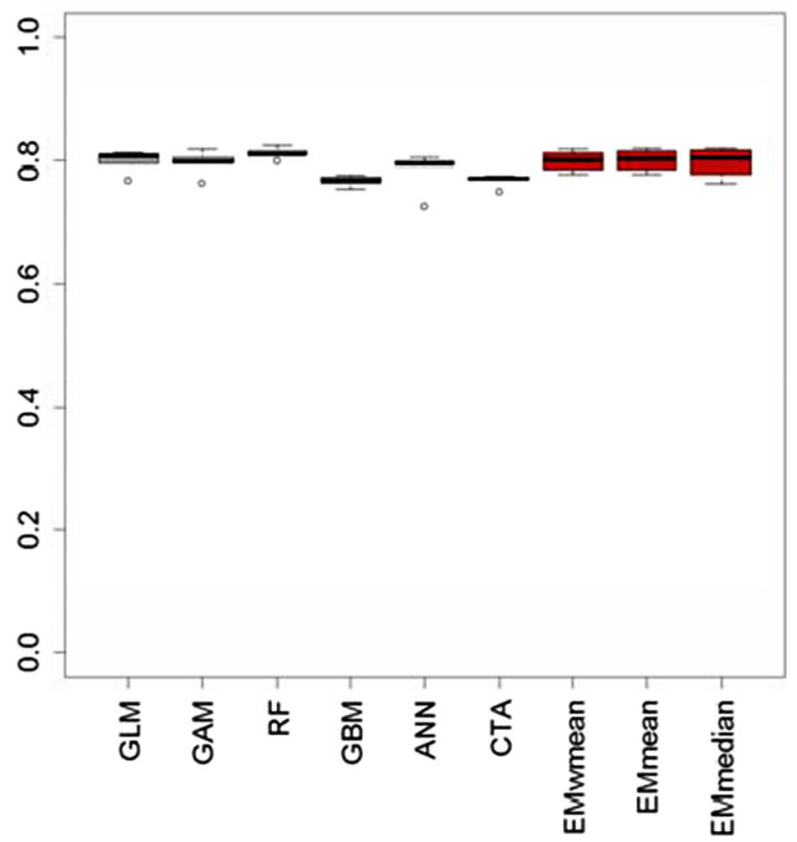

D Forest loss

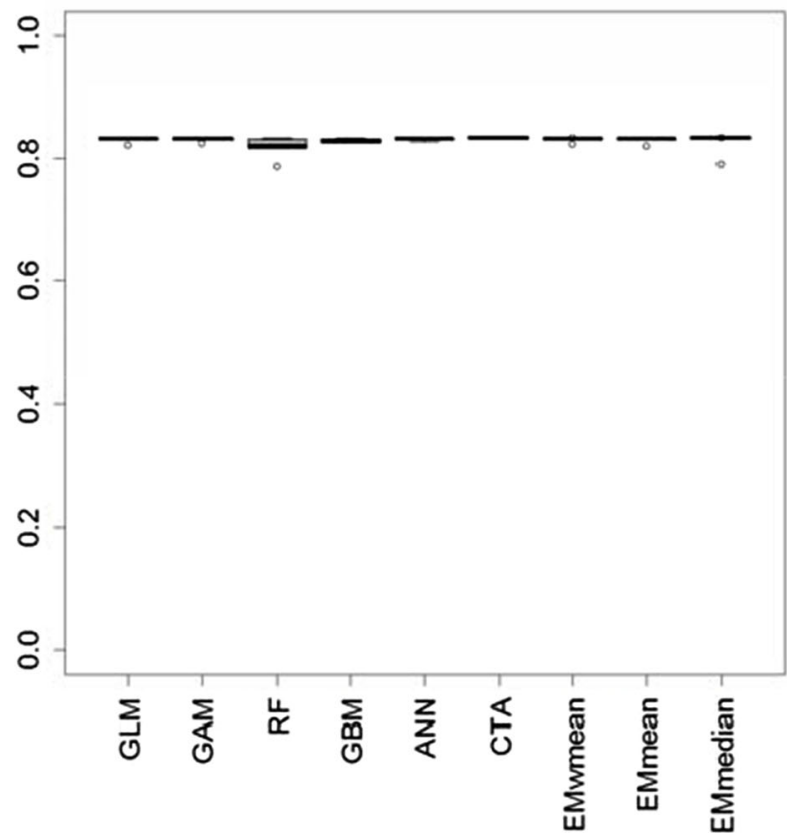

Fig. 4 Performance of models to assess forest gain and loss within the two time periods (period 1: 1880-1940; period 2: 1940-2010). Boxplots relied on five runs for each of the six model types (GLM, GAM, RF, GBM, ANN, CART). TSS indicated the degree of

than RF for forest gain (TSS 0.65; Fig. 4a, c). However, the differences in performance between RF and GBM were only marginal as the overlap between boxplots was considerable (Fig. 4a, c). GLM and ANN performed consistently low for forest gain (TSS 0.2-0.4; Fig. 4a, c). Strikingly, the performance for models of forest loss was

agreement between modelled predictions and observed data for each model type individually and between model types (model ensemble). EMwmean ensemble model, weighted mean; EMmean ensemble model, mean; EMmedian ensemble model, median

considerably higher (TSS 0.8; Fig. 4b, d) and much less varied across model types compared to forest gain whose TSS values ranged between 0.2 and 0.65 (Fig. 4a, c). The modelling ensembles were similar in performance compared to RF and GBM for both forest gain and loss (Fig. 4a-d). 
Table 1 Confusion matrices for forest gain and forest loss within period $1(1880-1940)$ and period 2 (1940-2010). $0=$ absence of forest loss or gain; 1 = presence of forest loss or gain. Maps of a, $\mathbf{c}$ are shown in Fig. $7 \mathrm{a}, \mathrm{b}$

\begin{tabular}{|c|c|c|c|c|c|}
\hline & & \multicolumn{2}{|c|}{ Ground Truth } & \multirow[t]{2}{*}{ No. classified pixels } & \multirow[t]{2}{*}{ User accuracy } \\
\hline & & 0 & 1 & & \\
\hline \multicolumn{6}{|c|}{ (a) Model performance for period 1; forest loss } \\
\hline \multirow[t]{2}{*}{ Modelled by ensemble } & 0 & 821,058 & 664 & 821,722 & 99.92 \\
\hline & 1 & 119,435 & 10,241 & 129,676 & 7.90 \\
\hline No. ground truth pixels & & 940,493 & 10,905 & 951,398 & NA \\
\hline Producer accuracy & & 87.30 & 93.91 & NA & 87.38 \\
\hline \multicolumn{6}{|c|}{ (b) Model performance for period 2; forest loss } \\
\hline \multirow[t]{2}{*}{ Modelled by ensemble } & 0 & 758,479 & 57 & 758,536 & 99.99 \\
\hline & 1 & 151,441 & 41,421 & 192,862 & 21.48 \\
\hline No. ground truth pixels & & 909,920 & 41,478 & 951,398 & NA \\
\hline Producer accuracy & & 83.36 & 99.86 & NA & 84.08 \\
\hline \multicolumn{6}{|c|}{ (c) Model performance for period 1; forest gain } \\
\hline \multirow[t]{2}{*}{ Modelled by ensemble } & 0 & 530,233 & 223 & 530,456 & 99.96 \\
\hline & 1 & 385,440 & 35,502 & 420,942 & 8.43 \\
\hline No. ground truth pixels & & 915,673 & 35,725 & 951,398 & NA \\
\hline Producer accuracy & & 57.91 & 99.38 & NA & 59.46 \\
\hline \multicolumn{6}{|c|}{ (d) Model performance for period 2; forest gain } \\
\hline \multirow[t]{2}{*}{ Modelled by ensemble } & 0 & 574,758 & 1261 & 576,019 & 99.78 \\
\hline & 1 & 303,103 & 72,276 & 375,379 & 19.25 \\
\hline No. ground truth pixels & & 877,861 & 73,537 & 951,398 & NA \\
\hline Producer accuracy & & 65.47 & 98.29 & NA & 68.01 \\
\hline
\end{tabular}

The confusion matrix showed that presence of both forest gain and loss were classified with high accuracy (>94\%; Table 1; producer accuracy; ground truth $=1$, ensemble $=1)$. Absence of forest loss was modelled with lower accuracy (83-87\%) and even lower for forest gain (58-65\%, Table 1; producer accuracy; ground truth $=0$, ensemble $=0$ ). The spatial allocation of forest change (user accuracy) was modelled reliably for forest absence (>99\%), whereas for forest presence user accuracy ranged between 8 and $21 \%$ for both forest gain and loss (Table 1).

\section{Model performance between time periods 1880-1940 and 1940-2010}

Comparing the overall pattern of model performance for 'forecasting the future' and 'hind-casting the past' revealed that RF and GBM perform highest for forest gain (TSS 0.6; Fig. 5a, c), while RF and ANN (TSS 0.82; Fig. 5b) as well as RF and CTA (TSS 0.82; Fig. 5d) performed highest for forest loss. GLM and ANN performed worst for forest gain (both projecting the future and hind-casting the past; TSS 0.2-0.5; Fig. 5a, c), while forest loss was modelled least by GLM and GAM (TSS 0.65-0.7; only Fig. 5d). Overall, RF consistently performed well for both projecting the future and hind-casting the past (Fig. 5a-d). The modelling ensembles performed less well than the best performing individual model types for both forest gain and loss (Fig. 5a-d).

The confusion matrix indicated that presence of forest loss and gain was predicted with accuracies $>89 \%$ for both predicting the future and hind-casting the past (Table 2; producer accuracy; ground truth $=1$, ensemble $=1$ ). In contrast, absence of forest was modelled with considerably lower accuracy for forest loss (83-87\%) and even lower for forest gain (61-65\%; Table 2; producer accuracy; ground truth $=0$, ensemble $=0$ ). The spatial allocation of forest change (user accuracy) was modelled accurately for forest absence between both periods (>99.4\%); however, the values for forest presence were lower (6-24\%, Table 2, user accuracy).

To summarize, the performance of models for forest loss was higher and less varied (TSS 0.8; within and between time periods) compared to those for forest gain (TSS $0.2-0.62$ ) for both assessments within and between periods (Figs. 4, 5). The confusion matrix within and between time periods indicated that presence of forest loss and gain was predicted with high accuracies $(>89 \%$; Tables 1,2$)$. In contrast, the accuracy of modelled absence of forest loss was lower (83-87\%) and even lower for forest gain (58-65\%; Tables 1, 2). We therefore conclude that forest loss was consistently modelled with considerably higher confidence than forest gain, irrespective of the time period considered. 


\section{A Forest gain}

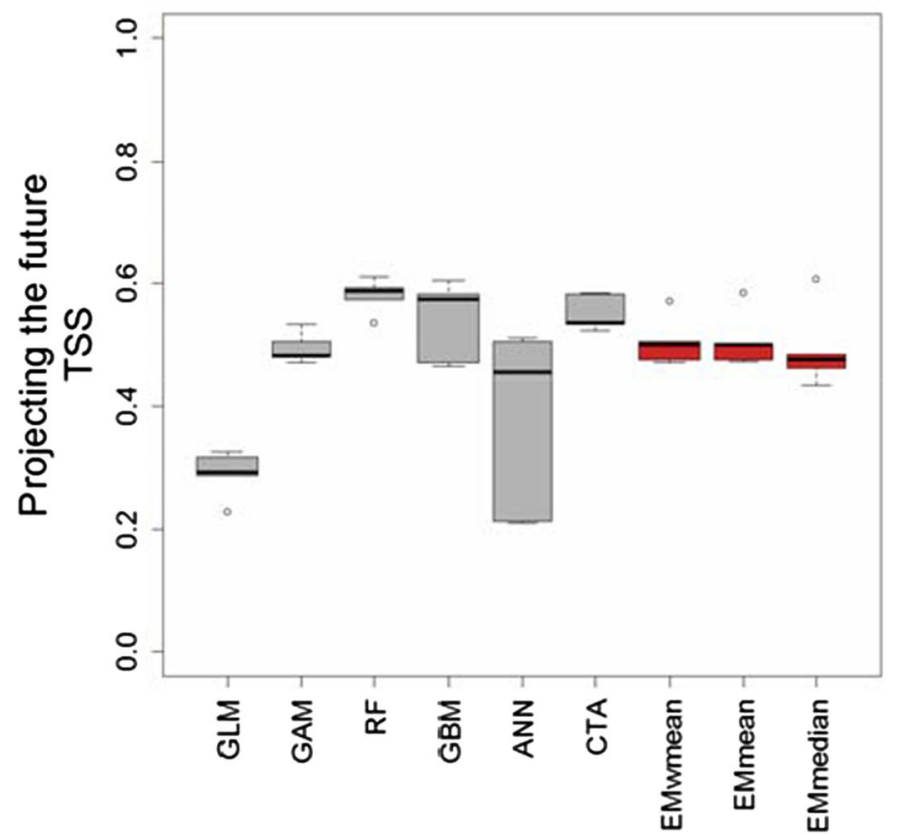

C Forest gain

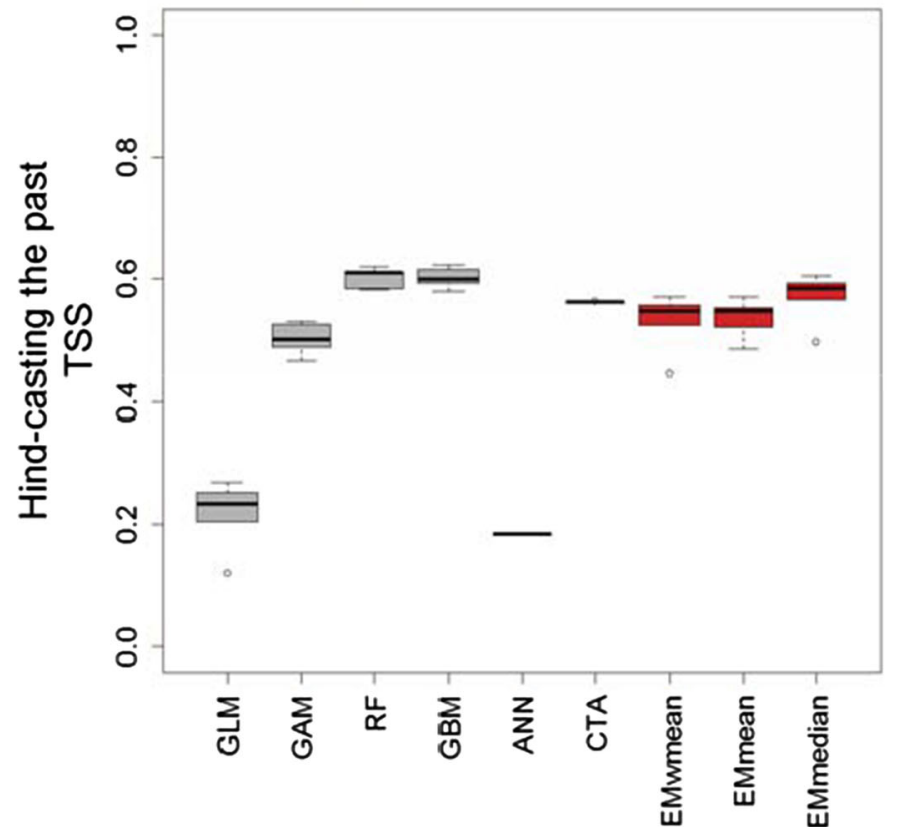

Fig. 5 Performance of models to assess forest gain and loss between the two time periods (period 1: 1880-1940; period 2: 1940-2010). 'Projecting the future': models calibrated with regression parameters of period 1 (1880-1940) were used to explain forest gain and loss of period 2 (1940-2010). 'Hind-casting the past': models calibrated with regression parameters of period 2 (1940-2010) were used to explain

\section{Uncertainty assessments: spatial projections} of ensemble models

An overall uncertainty assessment for ensemble models is provided in Fig. 6 (one randomly chosen ensemble model

\section{B Forest loss}

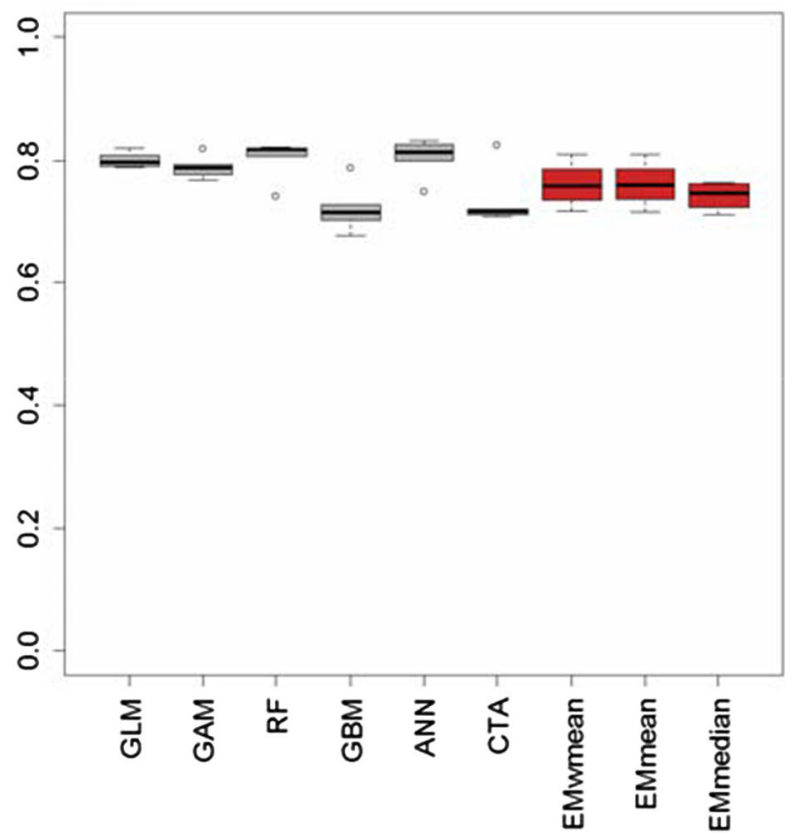

D Forest loss

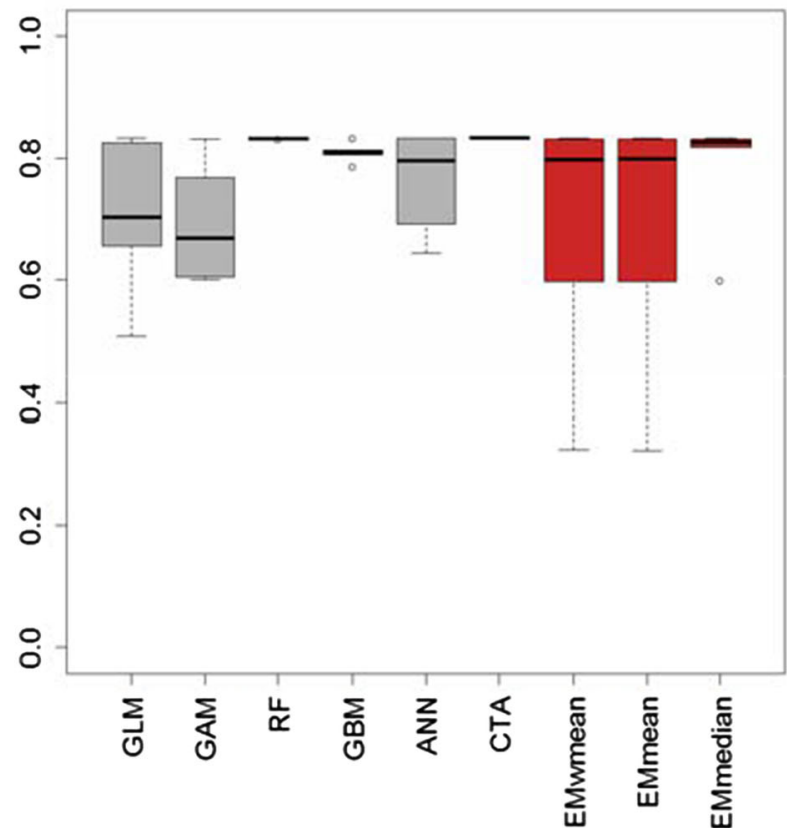

forest gain and loss of period 1 (1880-1940). Boxplots relied on five model runs for each of the six model types (GLM, GAM, RF, GBM, ANN, CART). TSS indicated the degree of agreement between modelled predictions and observed data for each model type individually and between model types (model ensemble)

run for projecting the future and for hind-casting the past) and 7 (overall uncertainty assessment for modelling forest cover). In line with the results for model performance (Figs. 4, 5; Appendix Figures B, C), these maps show that forest loss was modelled in spatially more confined areas 
Table 2 Confusion matrices for forest gain and forest loss between periods 1 and 2 (forecasting the future and hindcasting the past). $0=$ absence of forest loss or gain; $1=$ presence of forest loss or gain. A map of (a) and (c) is shown in Fig. 7c, d

\begin{tabular}{|c|c|c|c|c|c|}
\hline & & \multicolumn{2}{|c|}{ Ground Truth } & \multirow[t]{2}{*}{ No. classified pixels } & \multirow[t]{2}{*}{ User accuracy } \\
\hline & & 0 & 1 & & \\
\hline \multicolumn{6}{|c|}{ (a) Model performance between periods; forecasting forest loss } \\
\hline \multirow[t]{2}{*}{ Modelled by ensemble } & 0 & 791,336 & 4587 & 795,923 & 99.42 \\
\hline & 1 & 118,584 & 36,891 & 155,475 & 23.73 \\
\hline No. ground truth pixels & & 909,920 & 41,478 & 951,398 & NA \\
\hline Producer accuracy & & 86.97 & 88.94 & NA & 87.05 \\
\hline \multicolumn{6}{|c|}{ (b) Model performance between periods; hind-casting forest loss } \\
\hline \multirow[t]{2}{*}{ Modelled by ensemble } & 0 & 782,452 & 0 & 782,452 & 100.00 \\
\hline & 1 & 158,041 & 10,905 & 168,946 & 6.45 \\
\hline No. ground truth pixels & & 940,493 & 10,905 & 951,398 & NA \\
\hline Producer accuracy & & 83.20 & 100.00 & NA & 83.39 \\
\hline \multicolumn{6}{|c|}{ (c) Model performance between periods; forecasting forest gain } \\
\hline \multirow[t]{2}{*}{ Modelled by ensemble } & 0 & 534,002 & 152 & 534,154 & 99.97 \\
\hline & 1 & 343,859 & 73,385 & 417,244 & 17.59 \\
\hline No. ground truth pixels & & 877,861 & 73,537 & 951,398 & NA \\
\hline Producer accuracy & & 60.83 & 99.79 & NA & 63.84 \\
\hline \multicolumn{6}{|c|}{ (d) Model performance between periods; hind-casting forest gain } \\
\hline \multirow[t]{2}{*}{ Modelled by ensemble } & 0 & 596,590 & 1645 & 598,235 & 99.73 \\
\hline & 1 & 319,083 & 34,080 & 353,163 & 9.65 \\
\hline No. ground truth pixels & & 915,673 & 35,725 & 951,398 & NA \\
\hline Producer accuracy & & 65.15 & 95.40 & NA & 66.29 \\
\hline
\end{tabular}

(Fig. 7c, d), whereas forest gain was scattered across the entire study area (Fig. 7a, b). In addition, there was a trend that valley bottoms were modelled with higher uncertainty (less agreement between different model types) in contrast to higher-elevation areas (Fig. 7), likely due to the lack of other relevant land uses in valley bottoms which might compete with forest at higher elevations.

\section{Discussion}

\section{Drivers of forest-cover change}

Changes in land use usually originate from a complex combination of human interference with the environment and abiotic processes (Lambin and Meyfroidt 2011; Weisberg et al. 2013). Forests are a land use type that have particularly undergone major change in Europe during past decades (Fuchs et al. 2015; Vilén et al. 2015). During the twentieth century, forested areas increased due to land abandonment and active afforestation of low productivity agricultural land (Gold et al. 2006; Bellassen et al. 2011). In Switzerland, forests have increased by $21.6 \%$ over the past 120 years (Ginzler et al. 2011). The strongest increases were reported for the Alps, particularly in the southern part where the forested area doubled during this period (Ginzler et al. 2011). In line with this, we observed an increase in forest area of $25 \%$ between 1880 and 2010 in our mountainous study area. Although the reasons for forest change are generally related to socio-economic drivers which trigger natural reforestation following land abandonment of pastures (Gellrich et al. 2007), none of our variables attempting to describe the socio-economic conditions drove this pattern in our study area, possibly due to the difficulty of representing such data in a detailed spatially explicit form. Rather, forest-cover change was largely determined by distance to forest, a neighbourhood variable. Neighbourhood variables have been shown to be important drivers of land change as they may be used as proxies for cultivation and yield potential (Dendoncker et al. 2007; Gellrich et al. 2007; Rickebusch et al. 2007). In general, land close to forest has less favourable cultivation conditions than land far away from forest e.g., due to shading (Gellrich et al. 2007). Thus, distance to forest border may be an important driver of forest regrowth, particularly in mountainous environments (Gellrich et al. 2007). Also, it is likely that in a very spatially confined mountainous and remote areas, socio-demographic drivers such as changes in population may already have slowed down; thus, differences between the two time periods considered may not be pronounced. Also, our socio-economic variables were available at the resolution of a community which may be suitable to indicate rates of change, but not necessarily to identify locations of change. In contrast, forest-change 

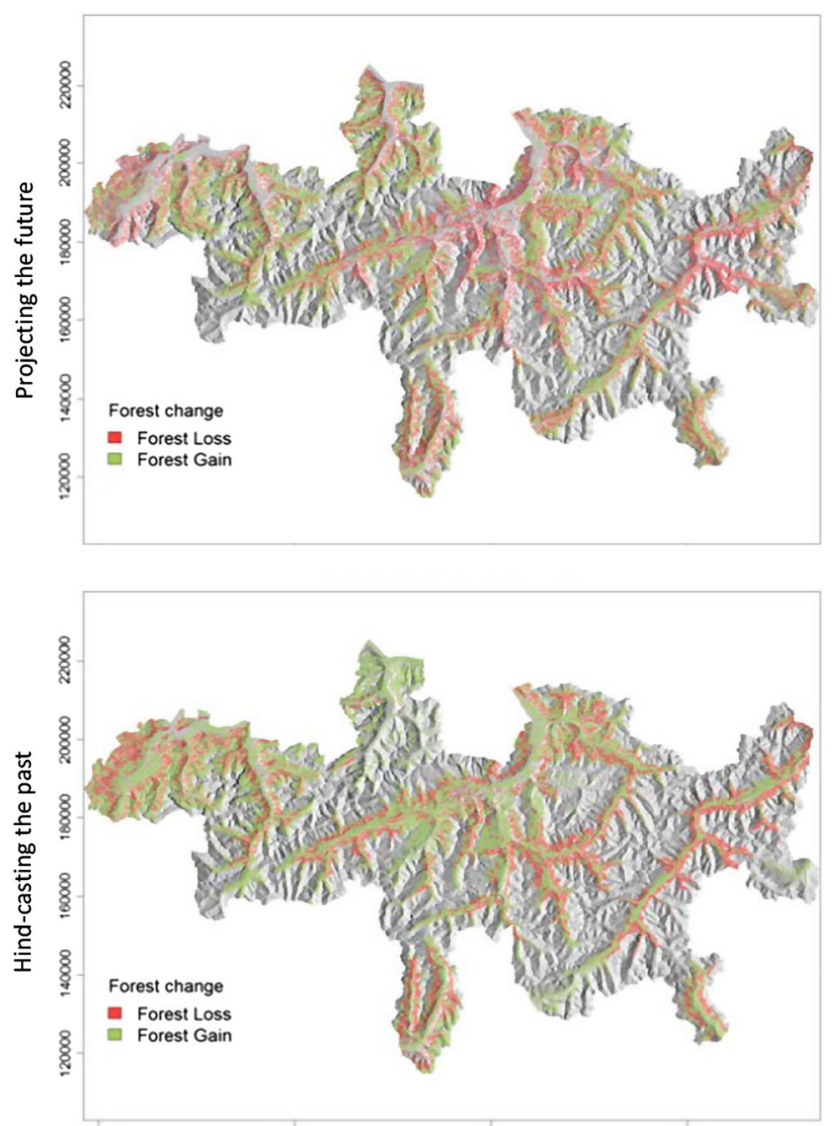

Fig. 6 Spatially explicit projections to assess forest-cover change between the two time periods: projecting future and hind-casting past forest-cover changes

assessments covering large areas with strong gradients ranging from the urbanized lowlands to remote mountainous areas have identified socio-economic variables as key determinants (Loran et al. in press). Similarly, the strong influence of socio-economic patterns on land-use change related to drastic change in the socio-political scheme has been experienced in most Eastern European countries over the past 30 years (Pazur et al. 2014).

\section{Ensemble modelling}

Land-change science draws on a wide array of concepts and techniques to gain a systematic understanding of causes and consequences of land dynamics. New standards and synthesis approaches have recently been

Fig. 7 Examples of agreement for forest presence; a forest gain for period 1 (Table 1c, 3); $\mathbf{b}$ projecting future forest gain based on models calibrated for period 1 (Table 2c, 3); c forest loss for period 1 (Table 1a); $\mathbf{d}$ projecting future forest loss (Table 2a). The uncertainty maps show agreement of model predictions (agreement of all 30 model predictions: six statistical models $\times$ five runs $=30$ ). A pixel with $>60 \%$ indicated that at least 18 model projections agreed that a pixel was forested
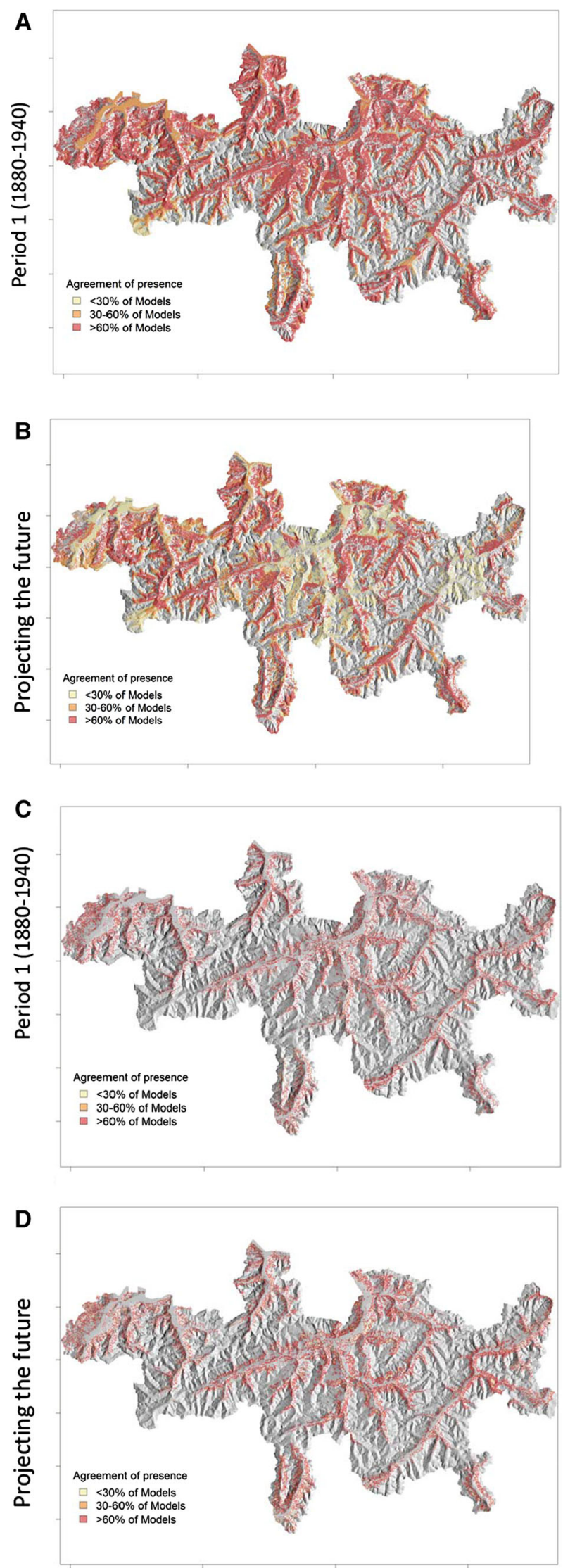
developed to account for the complex, multicausal nature of changes in land use (Magliocca et al. 2015). While many critical aspects such as data availability, data standardization, subjective variable selection and the implementation of qualitative information remain a challenge, ensemble modelling may provide a robust assessment of quantitative methods to compare results of different modelling concepts and approaches (Araujo and New 2007). Here, we evaluated ensemble modelling for different aspects of forest-cover change: first, by comparing and evaluating six different modelling approaches on two processes (forest gain, forest loss) and second, by projecting the processes into different time periods. As shown in Figs. 4 and 5, projections of forest-cover change differed considerably between the statistical methods used. Ensemble modelling can quantify the uncertainty originating from different statistical methods. As shown by Thuiller et al. (2009), models averaged into ensembles may perform better than individual modelling techniques. Therefore, if one modelling technique is selected and others were discarded, potentially important information could be lost.

Forest loss was modelled as spatially confined and with higher accuracy compared to forest gain. First, the projections for loss were much less varied across model types-in terms of model performance using TSS (Figs. 4, 5) and visually (Figs. 6, 7; Appendix Figures B, C). Second, TSS, the measure for comparing forestchange absence/presence, obtained higher values for forest loss (6-0.8) compared to forest gain $(0.2-0.6)$. Similar findings were indicated by producer's and user's accuracies for both within and between periods (Tables 1, 2), whereby forest presence was modelled with higher certainty at high-elevation areas (model agreement $>60 \%$ ) compared to valley bottoms (model agreement $<30 \%$; Fig. 7) for both time periods. Firstly, this indicated that no legacy effects on forest-cover change could be detected at the time and space scale considered. Second, the differences in model performance between forest gain and loss and in projections for valley bottoms and high-elevation sites could be mitigated by including other competing changes in land use (e.g., open land, settlement). However, historical assessments often lack historical information on the complete set of land use characteristics (Loran et al. 2016).

\section{Historical data remain a challenge when applied to quantitative land-change analyses}

There is a broad range of challenges when using historical data for land-use reconstructions across larger spatial scales, including data availability, spatial accuracy or methodology of data collection which may change over time (Kaim et al. 2014). We used Siegfried maps to estimate forest-cover change for the historical period between 1880 and 1940. This manually drawn forest delineation, which relies on a consistently applied technique of graphical triangulation, was compared to modern standardized land-use/land-cover data collated from the Swiss Vector25 of 2010. Not only was the Siegfried map series collated at a time prior to availability of systematic aerial photography, but the data were collated at different spatial resolutions across Switzerland (Jura and Plateau 1:25,000, Alps: 1:50,000) during different mapping campaigns (1870-1908 and 1917-1944 for the first and second Siegfried mapping campaign, respectively), resulting in a mapping process lasting several years. Therefore, the quality and quantity of forest data have considerably changed over the past 130 years and the conceptual and methodological inconsistencies between the data sets may lead to distortions of the actual forest area when comparing forest-cover change across the two time periods (period 1: 1880-1940; period 2: 1940-2010). A comparison between Siegfried maps and various independent estimates of forest area such as local forest reports or historical statistics for the period between 1880 and 1940 revealed that the Siegfried maps slightly overestimated forest area between 1880 and 1920, but matched independent forest data well between 1920 and 1940 (Ginzler et al. 2011; Loran et al. 2016). In contrast, data relying on modern aerial photography such as the Swiss Land Use Statistics or the Swiss TLM marginally underestimated data compiled from the National Forest Inventory (Ginzler et al. 2011; Loran et al. 2016). Although the historical Siegfried maps showed deviations from other sources to estimate forest area, such historical maps are prerequisites for conducting GIS-based legacy assessments on land change (Leyk et al. 2006; Haase et al. 2007).

Among explanatory variables used for modelling, we considered terrain as constant between the time periods considered, whereas socio-economic and climate variables varied. All models confirm that temperature significantly influenced forest-cover change. While all socio-economic data relied on similar empirical sources (statistical census data), climate maps covering the years 1880-2010 were based on data sources which were compiled using different methods and resolutions. Late nineteenth century climate maps (1880-1900) stemmed from multiproxy climate reconstructions, while early twentieth century climate maps (1901-1930) were developed from measurements of meteorological stations (Luterbacher et al. 2004; Xoplaki et al. 2005; Pauling et al. 2006). It is generally assumed that the quality of the climate data enhanced with time due to the change from reconstructed to measured data and the increase in resolution. However, although the reliability of the data remains unclear due to data scarcity, the maps 
have been widely applied for scientific purposes (Engler and Werner 2015).

\section{Conclusions}

The aims of this paper were (a) to assess the relative predictive power of socio-economic, climatic, physical and neighbourhood drivers in shaping historical forest-cover change for two time periods (period 1: 1880-1940; period 2: 1940-2010) using an ensemble modelling approach and (b) to analyse the performance of ensemble modelling in the context of a land-change assessment. We conclude that:

1. Distance to forest, a neighbourhood variable, explained the patterns of forest change best for both time periods between 1880 and 2010 for a spatially confined, high-elevation and politically stable area in Switzerland.

2. Ensemble models applied to land-change analysis provided a robust uncertainty assessment and allowed reliable conclusions on modelling land-change processes. Overall, forest loss was modelled with higher accuracy, less varied and as spatially more confined compared to forest gain.

3. There are no legacies. Calibrating a model for one time period and applying the parameter estimates to another was a promising tool to assess model robustness. However, we found that the modelled processes of forest gain and loss were indifferent to this legacy assessment as the dominating drivers prevailed, independent of the time period considered.

Acknowledgements We thank Niklaus E. Zimmermann, the Editors of REEC and two reviewers for valuable input on earlier drafts of this manuscript. Many thanks go also to Bronwyn Price who carefully improved our English. Samuel Berger and Marc Herrmann carefully collated the socio-economic data. This research financed by the FORECOM project (forest-cover changes in mountainous regionsdrivers, trajectories, implications, PSRP008/2010), supported by Grant from Switzerland through the Swiss contribution to the enlarged European Union.

\section{References}

Aggemyr E, Cousins SAO (2009) Landscape structure and land use history influence changes in island plant composition after 100 years. J Biogeogr 39:1645-1656

Allouche O, Tsoar A, Kadmon R (2006) Assessing the accuracy of species distribution models: prevalence, kappa and the true skill statistic (TSS). J Appl Ecol 43:1223-1232. doi:10.1111/j.13652664.2006.01214.x

Ameztegui A, Coll L, Brotons L, Ninot JM (2016) Land-use legacies rather than climate change are driving the recent upward shift of the mountain tree line in the Pyrenees. Glob Ecol Biogeogr 25:263-273. doi:10.1111/geb.12407
Anandhi A, Frei A, Pierson DC, Schneiderman EM, Zion MS, Lounsbury D, Matonse AH (2011) Examination of change factor methodologies for climate change impact assessment. Water Resour Res 47:W03501. doi:10.1029/2010WR009104

Araujo MB, New M (2007) Ensemble forecasting of species distributions. Trends Ecol Evol 22:42-47. doi:10.1016/j.tree. 2006.09.010

Bellassen V, Viovy N, Luyssaert S, le Maire G, Schelhaas M, Ciais P (2011) Reconstruction and attribution the carbon sink of European forests between 1950 and 2000. Glob Chance Biol 17:3274-3292. doi:10.1111/j.1365-2486.2011.02476.x

Bolliger J, Schulte LA, Burrows SN, Sickley TA, Mladenoff DJ (2004) Assessing restoration potentials of Wisconsin (USA) using historical landscape reconstructions. Restor Ecol 12:124-142

Breiman L (2001) Random forests. Mach Learn 45:5-32

Breiman L, Friedman J, Olshen R, Stone C (1984) Classification and regression trees. Wadsworth, New York

Bundesamt für Statistik (2015) Statistisches Lexikon der Schweiz. Historic collection. http://www.bfs.admin.ch/bfs/portal/de/index/ infothek/lexikon/lex/2

Callister KE, Griffioen PA, Avitabile SC, Haslem A, Kelly LT, Kenny SA, Nimmo DG, Farnsworth LM, Taylor RS, Watson SJ, Bennett AF, Clarke MF (2016) Historical maps from modern images: using remote sensing to model and map century-long vegetation change in a fire-prone region. PLoS ONE. doi:10. 1371/journal.pone. 0150808

Congalton RG, Green K (2009) Assessing the accuracy of remotely sensed data: principals and practices, 2nd edn. CRC Press, Taylor and Francis Group, Boca Raton

Dendoncker N, Rounsevell M, Bogaert P (2007) Spatial analysis and modelling of land use distributions in Belgium. Comput Environ Urban Syst 31:188-205. doi:10.1016/j.compenvurbsys.2006.06. 004

Engler S, Werner JP (2015) Processes prior and during the early 18th century Irish famines-weather extremes and migration. Climate 3:1035-1056. doi:10.3390/cli3041035

Engler R, Waser LT, Zimmermann NE, Schaub M, Berdos S, Ginzler C, Psomas A (2013) Combining ensemble modeling and remote sensing for mapping individual tree species at high spatial resolution. For Ecol Manag 310:64-73. doi:10.1016/j.foreco. 2013.07.059

Freeman EA, Moisen GG (2008) A comparison of the performance of threshold criteria for binary classification in terms of predicted prevalence and kappa. Ecol Model 217:48-58. doi:10.1016/j. ecolmodel.2008.05.015

Fuchs R, Herold M, Verburg PH, Clevers JGPW, Eberle J (2015) Gross changes in reconstructions of historic land cover/use for Europe between 1900 and 2010. Glob Change Biol 21:299-313. doi: $10.1111 /$ gcb. 12714

Gellrich M, Baur P, Zimmermann N (2007) Natural forest regrowth as a proxy variable for agricultural land abandonment in the Swiss mountains: a spatial statistical model based on geophysical and socio-economic variables. Environ Model Assess 12:269-278. doi:10.1007/s10666-006-9062-6

Ginzler C, Brändli UB, Hägeli M (2011) Waldflächenentwicklung der letzten 120 Jahre in der Schweiz. Schweizerische Zeitschrift für Forstwesen 162:337-343

Gold S, Korotkov A, Sasse V (2006) The development of European forest resources, 1950 to 2000. For Policy Econ 8:183-192

Haase D, Walz U, Neubert M, Rosenberg M (2007) Changes to Central European landscapes-analysing historical maps to approach current environmental issues, examples from Saxony, Central Germany. Land Use Policy 24:248-263. doi:10.1016/j. landusepol.2005.09.003 
Hastie T, Tibshirani R (1986) Generalized additive models. Stat Sci $1: 297-318$

Kaim D, Kozak J, Ostafin K, Dobosz M, Ostapowicz K, Kolecka N, Gimmi U (2014) Uncertainty in historical land-use reconstructions with topographic maps. Quaest Geogr 33:57-63. doi:10. 2478/quageo-2014-0029

Kulakowski D, Bebi P, Rixen C (2011) The interacting effects of land use change, climate change and suppression of natural disturbances on landscape forest structure in the Swiss Alps. Oikos 120:216-225. doi:10.1111/j.1600-0706.2010.18726.x

Lambin E, Meyfroidt P (2011) Global land use, economic globalization, and the looming land scarcity. Proc Natl Acad Sci USA 108:3465-3472. doi:10.1073/pnas.1100480108

Lambin EF, Turner BL, Geist HJ, Agbola SB, Angelsen A, Bruce JW, Coomes O, Dirzo R, Fischer G, Folke C, George PS, Homewood $\mathrm{K}$, Imbernon $\mathrm{J}$, Leemans $\mathrm{R}$, Li X, Moran EF, Morimore M, Ramakrishnan PS, Richards JF, Skanes H, Steffen WL, Stone GD, Svedin U, Veldkamp TA, Vogel C, Xu J (2001) The causes of land use and land-cover change: moving beyond the myths. Glob Environ Change 11:261-269. doi:10.1016/S09593780(01)00007-3

Leyk S, Boesch R, Weibel R (2006) Saliency and semantic processing: extracting forest cover from historical topographic maps. Pattern Recogn 39:953-968. doi:10.1016/j.patcog.2005. 10.018

Loran C, Ginzler C, Bürgi M (2016) Evaluating forest transition based on a multi-scale approach: forest area dynamics in Switzerland 1850-2000. Reg Environ Change. doi:10.1007/ s10113-015-0911-1

Loran C, Munteanu C, Verburg P, Schmatz DR, Bürgi M, Zimmermann NE (in press) Long-term change in drivers of forest cover dynamics: an analysis for Switzerland (1850-2000). Reg Environ Change

Luterbacher J, Dietrich D, Xoplaki E, Grosjean M, Wanner H (2004) European seasonal and annual temperature variability, trends, and extremes since 1500. Science 303:1499-1503. doi:10.1126/ science. 1093877

Magliocca NR, Rudel TK, Verburg PH, McConneell WJ, Mertz O, Gerstner K, Heinimann A, Ellis EC (2015) Synthesis and land change science: methodological patterns, challenges, and guidelines. Reg Environ Change 15:211-226. doi:10.1007/s10113014-0626-8

Marmion M, Parviainen M, Luoto M, Heikkinen RK, Thuiller W (2009) Evaluation of consensus methods in predictive species distribution modelling. Divers Distrib 15:59-69. doi:10.1111/j. 1472-4642.2008.00491.x

McCullagh P, Nelder JA (1989) Generalized linear models, 2nd edn. Chapman and Hall, London

Pauling AJ, Luterbacher C, Casty H, Wanner H (2006) Five hundred years of gridded high-resolution precipitation reconstructions over Europe and the connection to large-scale circulation. Clim Dyn 26:387-405. doi:10.1007/s00382-005-0090-8

Pazur R, Lieskovsky J, Fernanec J, Othael J (2014) Spatial determinants of abandonment of large-scale arable lands and managed grasslands in Slovakia during the periods of postsocialist transition and European Union accession. Appl Geogr 54:118-128. doi:10.1016/j.apgeog.2014.07.014

Regos A, D'Amen M, Titeux N, Herrando S, Guisan A, Bortons L (2016) Predicting the future effectiveness of protected areas for bird conservation in Mediterranean ecosystems under climate change and noel fire regime scenarios. Divers Distrib 22:83-96. doi:10.1111/ddi.12375
Rickebusch S, Gellrich M, Lischke H, Guisan A, Zimmermann NE (2007) Combining probabilistic land-use change and tree population dynamics modelling to simulate responses in mountain forests. Ecol Model 209:157-168. doi:10.1016/j.ecolmodel. 2007.06.027

Ridgeway G (1999) The state of boosting. Comput Sci Stat $31: 172-181$

Riley SJ, DeGloria SD, Elliot R (1999) A terrain ruggedness index that quantifies topographic heterogeneity. Intermt J Sci 5:23-27

Ripley BD (1996) Pattern recognition and neural networks. Cambridge University Press, Cambridge. ISBN 0521460867

Rounsevell MDA, Pedroli B, Erb KH, Gramberger M, Busck AG, Haberl H, Kristensen S, Kuemmerle T, Lavorel S, Lindner M, Lotze-Campen H, Metzger MJ, Murray-Rust D, Popp A, PerezSoba M, Reenberg A, Vadineanu A, Verburg PH, Wolfslehner B (2012) Challenges for land system science. Land Use Policy 29:899-910. doi:10.1016/j.landusepol.2012.01.007

Scales KL, Miller PI, Ingram SN, Hazen EL, Bograd SJ, Phillips RA (2016) Identifying predictable foraging habitats for a wideranging marine predator using ensemble ecological niche models. Divers Distrib 22:212-224. doi:10.1111/ddi.12389

SFSO, Swiss Federal Statistical Office (2013) Land use in Switzerland: Results of the Swiss land use statistics. SFSO, Neuchatel

Siegfriedkarten (1870-1922) Siegfriedkarten. In: Schweizerische Landestopographie. http://www.swisstopo.ch/de/maps/ak/tk.htm

swissTLM $^{3 \mathrm{D}}$ (2015) Vectorized national map 1:25,000. Bundesamt für Landestopographie. http://www.swisstopo.admin.ch. Wabern, Bern

Swisstopo (2016) Vektor 25. Bundesamt für Landestopographie. http://www.swisstopo.admin.ch. Wabern, Bern

Thornton PE, Running SW, White MA (1997) Generating surfaces of daily meteorological variables over large regions of complex terrain. J Hydrol 190:214-251. doi:10.1016/S00221694(96)03128-9

Thuiller W, Lafourcade B, Engerl R, Araujo MB (2009) BIOMOD—a platform for ensembel forecasting of species distributions. Ecography 32:369-373. doi:10.1111/j.1600-0587.2008.05742.x

Van Asselen S, Verburg PH (2013) Land cover change or land-use intensification: simulating land system change with a globalscale land change model. Glob Change Biol 19:3648-3667. doi: $10.1111 / \mathrm{gcb} .12331$

Vilén T, Cienciala E, Schelhaas MJ, Verkerk PJ, Lindner M, Peltola $\mathrm{H}$ (2015) Increasing carbon sinks in European forests: effects of afforestation and changes in mean growing stock volume. Forestry. doi:10.1093/forestry/cpv034

Wang Q, Ren QF, Liu JF (2016) Identification and apportionment of the drivers of land use change on a regional scale: unbiased recursive partitioning-based stochastic model application. Agric Ecosyst Environ 217:99-110. doi:10.1016/j.agee.2015.11.004

Weisberg PJ, Shandra O, Becker ME (2013) Landscape influences on recent timberline shifts in the Carpathian mountains: abiotic influences modulate effects of land-use change. Arct Antarct Alp Res 45:404-414. doi:10.1657/1938-4246-45.3.404

Wilson MFJ, O'Connell B, Brown C, Guinan JC, Grehan AJ (2007) Multiscale terrain analysis of multibeam bathymetry data for habitat mapping on the continental slope. Mar Geod 30:3-35. doi:10.1080/01490410701295962

Xoplaki E, Luterbacher J, Paeth H, Dietrich D, Steiner N, Grosjean M, Wanner H (2005) European spring and autumn temperature variability and change of extremes over the last half millennium. Geophys Res Lett 32:L15713. doi:10.1029/2005GL023424 